\title{
Propriedade Intelectual em Empresas Públicas: uma análise dos depósitos de marcas da Embrapa \author{
trademarks applications
} \\ Intellectual Property in Public Companies: an analysis of Embrapa's
}

\author{
Glauber Adenir Soares Preto ${ }^{1}$ \\ Cíntia Brenner Acosta Franco ${ }^{1}$ \\ Kelly Lissandra Bruch ${ }^{2}$ \\ ${ }^{1}$ Instituto Federal do Rio Grande do Sul, Porto Alegre, RS, Brasil \\ ${ }^{2}$ Universidade Federal do Rio Grande do Sul, Porto Alegre, RS, Brasil
}

\begin{abstract}
Resumo
A proposta deste artigo é mostrar os aspectos relevantes acerca do registro de marcas de uma empresa pública no Brasil, em especial, o panorama da Empresa Brasileira de Pesquisa Agropecuária (Embrapa). O objetivo é analisar os dados que permeiam os pedidos de registro de marca no Brasil, as questões sobre como a empresa trabalha e a gestão desses ativos intangíveis para o desenvolvimento da empresa e do ambiente em que ela está inserida. Para o desenvolvimento da pesquisa, foi realizado um estudo de caso, de natureza exploratória e descritiva, com abordagem mista (quanti-qualitativa), por meio de entrevistas de colaboradores da instituição e por pesquisa nas principais bases de dados referentes à propriedade intelectual, entre os anos de 1970 até 2018, utilizando-se como termo de busca a denominação "Embrapa" na titularidade. Todas as plataformas pesquisadas apresentaram número crescente de pedidos ao longo dos anos. Na base do INPI, foram encontrados 484 pedidos de registro de marcas, sendo em sua maioria marcas nominativas. Pode-se concluir que é perceptível o avanço na proteção de marcas pela Embrapa, esse avanço pode se dar devido aos investimentos e às ações do mercado. Todavia, apesar de a empresa possuir um processo para encaminhamento de registro de marcas relativamente conhecido, esse procedimento não está documentado e verificou-se a necessidade de se realizar a documentação do processo, bem como a orientação $e$ a capacitação das equipes para proteção e execução de forma correta dos procedimentos de registros de marcas junto ao INPI.
\end{abstract}

Palavras-chave: Signos Distintivos. Propriedade Industrial. Prospecção Tecnológica.

\section{Abstract}

The purpose of this article is to show the relevant aspects about the applications of trademarks from a public company in Brazil, in particular, the panorama of the Brazilian Agricultural Research Corporation (Embrapa). The objective is to analyze the data of trademark applications in Brazil, questions about how the company works and the management of these intangible assets for the development of the company and the environment in which it operates. For the development of the research, an exploratory and descriptive case study was carried out, with a mixed approach (quanti-qualitative), through interviews of employees of the institution and by research in the main databases related to intellectual property, among the years 1970 to 2018, using the term "Embrapa" as the search term. All platforms surveyed had an increasing number of orders over the years. At the INPI base, 484 trademark applications were found, most of which are registered trademarks. It can be concluded that the advance in the protection of trademarks by Embrapa is noticeable, this advance may occur due to investments and market actions. However, despite the fact that the company has a relatively well-known trademark registration process, this procedure is not documented and there was a need to carry out the process documentation, as well as the guidance and training of the teams for protection and enforcement correctly the procedures for registering trademarks with the INPI.

Keywords: Distinctive Signs. Brands. Technological Prospecting.

Área Tecnológica: Propriedade Intelectual. 


\section{Introdução}

A prospecção tecnológica é uma atividade realizada com o objetivo de mapear de forma sistemática o desenvolvimento científico e tecnológico capaz de influenciar de forma significativa a indústria, a economia e a sociedade. O mapeamento de tecnologias relacionadas ao principal ativo da empresa, a marca, passa a ter um papel de extrema importância, pois, além de apresentar a empresa, também evidencia a imagem desta, que é direcionada para o mercado (RODRIGUES, 2017).

A marca no Brasil é definida e regulada por meio da Lei Federal n. 9.279, de 14 de maio de 1996, conhecida também como Lei da Propriedade Industrial ou LPI. Assim define essa Lei: "[...] como sinal distintivo visualmente perceptível" (BRASIL, 1996, art. 22). O registro da marca pode ser realizado nos seguintes formatos: nominativa, figurativa, mista ou tridimensional, sendo esta um artifício de referência para o consumidor no momento de sua compra (INPI, 2020).

O simples fato de possuir um signo capaz de distinguir uma empresa dentro do mercado em que atua, seja esta empresa pública ou privada, não significa que essa marca está sendo gerida de forma que os aspectos intangíveis estejam sendo explorados e aproveitados ao máximo. Segundo Rodrigues (2017), a marca deve ser bem gerida, pois, quando uma organização possui uma imagem de seus serviços ou produtos bem avaliados no mercado, são conferidos a ela adjetivos e valores, deixando de ter apenas a função de dar nome a uma empresa. Também se torna um fator importante para o desenvolvimento das organizações, passando a representar todo o conjunto de valores e toda a complexidade da organização.

Diante da importância das marcas para a sociedade, segundo Albuquerque (2015), faz-se necessário protegê-las comercial e juridicamente para garantir que a marca de uma empresa não seja usada de forma indevida, registrando-a junto aos órgãos competentes e impedindo que terceiros a utilizem sem autorização. O órgão responsável por receber os pedidos de registro de marcas no Brasil é o Instituto Nacional da Propriedade Industrial (INPI), autarquia federal, criada a partir da década de 1970, vinculada atualmente ao Ministério da Economia (INPI, 2019).

A partir da discussão realizada inicialmente, este estudo pretende analisar as potencialidades e as fragilidades da gestão de marcas da Empresa Brasileira de Pesquisa Agropecuária, a Embrapa, apresentando uma contribuição para essa área da propriedade industrial na empresa, uma vez que outras já foram objetos de estudos anteriores. Como desdobramento do objetivo geral de pesquisa, evidencia-se como objetivos específicos: i) mapear as marcas depositadas pela Embrapa; ii) identificar as práticas de gestão de proteção de marcas adotadas; e, por fim, iii) identificar as potencialidades e as fragilidades nas práticas de gestão de proteção de marcas adotadas pela Empresa. Para alcançar esses objetivos, o presente artigo foi organizado em cinco partes. Além desta introdução, apresenta-se o referencial teórico, a metodologia, os resultados $e$ a discussão e as considerações finais.

\section{Referencial Teórico}

Desde a antiguidade, o homem demonstra o desejo de identificar sua própria criação. Artefatos pré-históricos e objetos antigos de cerâmica encontrados na Grécia e em Roma já traziam marcas compostas de iniciais, nomes, símbolos e emblemas de seus fabricantes. Até mesmo 
produtos da Índia de cerca de 1.300 a.C. traziam algum tipo de marcação (PASTORE, 2018; ABAPI, 1998). Era comum nos primeiros modelos de civilização que os artesãos assinassem seus trabalhos com siglas ou símbolos próprios, como forma de distinção dos demais. Já no período medieval, com o desenvolvimento do comércio, o uso de signos para distinguir as mercadorias dos comerciantes e fabricantes se expandiu. Além de atrair consumidores, as marcas também tinham outros objetivos, como atestar a qualidade de um produto e garantir os monopólios existentes na época. Porém, sua importância econômica ainda era limitada.

A partir da industrialização, as marcas começam a desempenhar um importante papel, tornando-se um fator-chave no mundo moderno em que o comércio internacional $e$ as economias são orientadas para o mercado (OMPI, 2004). Uma variedade de produtos na mesma categoria passou a ser ofertada aos consumidores, com diferentes níveis de qualidade, preço $e$ outras características, sendo a marca elemento fundamental de diferenciação.

Assim, podemos concluir que as marcas evoluíram profundamente desde suas origens, visto que, na Idade Média, por exemplo, se destinavam apenas a identificar o fabricante dos produtos vendidos, passando por mudanças decorrentes da Revolução Francesa e da Revolução Industrial até os dias atuais, em que as marcas se referem aos produtos em si, tendo por intenção individualizá-los cada vez mais, distingui-los dos concorrentes e comunicar valores intangíveis. (PASTORE, 2018, p. 21)

Para a World Intellectual Property Organization, em português Organização Mundial da Propriedade Intelectual (OMPI), as marcas incentivam as empresas a manter e a melhorar a qualidade de seus produtos e serviços para atender às expectativas de seus consumidores, recompensando aqueles que entregam bens de alta qualidade e estimulando o progresso econômico (OMPI, 2004).

As marcas são muito mais que sinais capazes de distinguir um produto ou serviço dos demais. Elas carregam um conjunto de significados intangíveis e que, segundo Pastore (2018), apresentam diferentes funções: para a empresa é um ativo de negócio que deve gerar retorno; para o consumidor, a representação de valores e um conjunto de significados positivos ou negativos construído na interação ao longo do tempo com a marca.

Uma marca bem desenvolvida é um ativo de valor para a maior parte das empresas e, em alguns casos, esse valor pode superar os demais ativos tangíveis da empresa. Um estudo da Brand Finance, divulgado em janeiro de 2019, revelou que Amazon, Apple e Google são as três marcas mais valiosas do mundo, ultrapassando mais de 140 bilhões de dólares cada (BRAND FINANCE, 2019). As marcas contribuem para a construção da imagem e da reputação de produtos e de empresas, gerando confiança por parte dos consumidores e identificação com os valores representados. Possuir uma marca forte é uma importante vantagem competitiva. Dessa forma, proteger a marca significa proteger o negócio.

No Brasil, a proteção de marcas se dá por meio do registro, estabelecido pela já citada LPI, o que garante o direito exclusivo de inibir terceiros de produzir, utilizar, colocar à venda, vender, importar, exportar e/ou ter em estoque produto com marca igual ou semelhante a ponto de confundir os consumidores. Portanto, sem o registro não há meios legais de impedir que concorrentes utilizem a mesma marca ou similar. Assim, é essencial garantir que a(s) marca(s) de uma empresa estejam registradas em seus mercados de atuação. O órgão responsável por receber e analisar os pedidos de registro de marcas no país é o INPI. 
A LPI define, em seu artigo 123, quatro diferentes naturezas de marca: de produto; de serviço; coletiva; e de certificação:

Para os efeitos desta Lei, considera-se:

I - marca de produto ou serviço: aquela usada para distinguir produto ou serviço de outro idêntico, semelhante ou afim, de origem diversa;

II - marca de certificação: aquela usada para atestar a conformidade de um produto ou serviço com determinadas normas ou especificações técnicas, notadamente quanto à qualidade, natureza, material utilizado e metodologia empregada; $e$

III - marca coletiva: aquela usada para identificar produtos ou serviços provindos de membros de uma determinada entidade. (BRASIL, 1996, art. 123)

Quanto à forma de apresentação, as marcas podem ser nominativas, figurativas, mistas ou tridimensionais. As marcas nominativas são constituídas por uma ou mais palavras, incluindo neologismos e combinações de letras e algarismos. As figurativas podem ser compostas de desenhos, figuras, imagens, símbolos, formas fantasiosas de letras ou algarismos, ideogramas $e$ palavras formadas por letras de alfabetos distintos da língua nacional. As mistas, ou compostas, combinam elementos nominativos e figurativos e, por vezes, trazem palavras em que a grafia se apresenta de forma estilizada. Já a marca tridimensional pode ser protegida quando a forma plástica de um produto é capaz de distingui-lo dos demais (INPI, 2020). Atualmente, novas formas de apresentação estão sendo solicitadas, como é o caso da marca de posição.

O registro de marcas está sujeito a três princípios: veracidade, territorialidade e especialidade. A veracidade diz que uma marca não pode ser enganosa, confundir o consumidor, nem indicar propriedades inverídicas. A proteção é exclusiva ao território do país ou bloco regional onde foi feito o registro, portanto, não existe marca internacional. Já a especialidade refere-se à limitação da exclusividade, ou seja, a proteção é restrita aos produtos ou serviços que distingue, que, na prática, se traduz nas classes de registro (INPI, 2020).

O Brasil adota a Classificação Internacional de Produtos e Serviços de Nice (NCL), que possui uma lista de 45 classes que categoriza os produtos e os serviços pertencentes a cada classe (INPI, 2020). O sistema é dividido entre produtos listados nas classes 1 a 34 e serviços listados nas classes 35 a 45. É importante saber que as classes e as listas não são exaustivas, ou seja, não incluem todos os tipos de produtos e serviços que existem (INPI, 2020).

O registro é válido por 10 anos, prorrogáveis por períodos iguais e sucessivos, contados a partir da concessão do registro, tendo o titular o dever de utilizar a marca e solicitar a prorrogação da vigência (INPI, 2020). O artigo 130 da LPI estabelece os direitos do titular, que incluem o zelo pela integridade e reputação, assim como a cedência do registro ou pedido de registro $e$ o licenciamento de uso da marca. A perda do direito ocorre na expiração do prazo de vigência do registro se não for solicitada a prorrogação; bem como por renúncia; por caducidade, caso a marca não tenha seu uso iniciado no Brasil ou se uso for interrompido por mais de cinco anos consecutivos; ou ainda, se, no mesmo período, a marca tiver sido utilizada com modificação.

A LPI também estabelece as condições de registrabilidade, que são organizadas em três categorias: distintividade, licitude e disponibilidade. A primeira diz respeito à capacidade da marca de distinguir objetivamente os produtos ou serviços aos quais se refere, não sendo possível registrar signos que não demonstrem tal capacidade, como aqueles de caráter genérico, 
comum, descritivo ou comumente utilizados para designar uma característica do produto ou serviço. A condição de licitude refere-se ao entendimento de que a marca não engane ou iluda o consumidor, no sentido de estar associada à falsa indicação quanto à procedência, à origem e/ou à qualidade, a símbolos nacionais e/ou estrangeiros, que atentem contra a ordem pública, moral, dos bons costumes e a liberdade de crença, por exemplo. E, por fim, a marca deve estar disponível para registro, não pertencendo a terceiros. Essa condição contempla os nomes empresariais, nomes artísticos, nomes de bandas, nomes e símbolos de prêmios e eventos esportivos.

Há ainda a figura das marcas de alto renome e notoriamente conhecidas. A marca registrada no Brasil que for considerada de alto renome goza de proteção especial em todos os ramos de atividade, sendo uma exceção ao princípio da especialidade. As marcas de alto renome são amplamente conhecidas pelo mercado, têm grande reconhecimento, prestígio e reputação positiva. É em face desse reconhecimento que se pode solicitar junto ao INPI a sua proteção como marca de alto renome. Já as marcas notoriamente conhecidas recebem proteção especial independentemente de estarem registradas ou não no país, configurando uma exceção ao princípio da territorialidade. Nesse caso, a proteção fica limitada apenas ao ramo de atuação. Esses mecanismos servem para impedir que terceiros associem seus produtos ou serviços a essas marcas, se aproveitando de seu diferencial competitivo já consolidado no mercado, por meio de um comportamento parasitário.

A empresa titular da marca também pode desenvolver o seu licenciamento, o que pode ser vantajoso para empresas que decidem ultrapassar seu core business e atuar em diferentes segmentos do mercado (SALVADOR; IKEDA; CRESCITELLI, 2017). Caso a empresa participe de mercados estrangeiros e precise construir uma reputação internacional, deve-se avaliar o registro de marca em outros países. Existem três formas de fazer esse tipo de proteção: via nacional, apresentando o pedido à autoridade competente em cada país que se deseja a proteção; via regional, solicitando o registro a um sistema regional de marcas, com validade nos territórios de todos os países membros; ou via convencional, utilizando o Sistema de Madri, caso o país sede da empresa seja membro deste (OMPI, 2004). O Brasil firmou em 2019 o Protocolo de Madri, junto à OMPI, o que permitirá que as empresas brasileiras solicitem por meio deste a proteção de suas marcas em todos os países signatários, bem como empresas de países signatários poderão solicitar, desde sua origem, a proteção de suas marcas no Brasil.

\subsection{Empresa Brasileira de Pesquisa Agropecuária (Embrapa)}

A Empresa Brasileira de Pesquisa Agropecuária (Embrapa), vinculada ao Ministério da Agricultura, Pecuária e Abastecimento, foi criada em 26 de abril de 1973. Sua missão é viabilizar soluções de pesquisa, desenvolvimento e inovação para a sustentabilidade da agricultura, em benefício da sociedade brasileira. Atua por meio de Unidades Descentralizadas de Pesquisa e de Serviços e de Unidades Administrativas, estando presente em quase todos os estados e nos mais diferentes biomas brasileiros.

Modelagens inovadoras, como as Unidades Mistas de Pesquisa (UMiPs), pretendem criar um ambiente de colaboração de pesquisa por meio do compartilhamento de estruturas e de equipes, ampliando a capacidade de desenvolvimento de novas tecnologias e soluções. Atualmente, são duas UMiPs no Brasil, a Unidade Mista de Pesquisa em Genômica Aplicada a Mudanças Climáticas (UMiP GenClima), fruto de uma parceria entre a Embrapa e a Universidade 
Estadual de Campinas (Unicamp); e a Unidade Mista de Pesquisa e Transferência de Tecnologia (UMIPTT) do Sudoeste do Paraná, que nasceu de um acordo de cooperação técnica entre a Embrapa, a Universidade Tecnológica Federal do Paraná (UTFPR) e o Instituto Agronômico do Paraná (lapar). A Embrapa conta com 9.460 empregados, dos quais 2.424 são pesquisadores, que, em sua grande parte (84\%), possuem doutorado ou pós-doutorado (EMBRAPA, 2019a).

A Embrapa coordena o Sistema Nacional de Pesquisa Agropecuária (SNPA), constituído por instituições públicas federais, estaduais, universidades, empresas privadas e fundações, que, de forma cooperada, executam pesquisas nas diferentes áreas geográficas e campos do conhecimento científico. Tecnologias geradas pelo SNPA mudaram a agricultura brasileira e ajudaram o país a superar as barreiras que limitavam a sua produção. Por meio da pesquisa, o Cerrado foi incorporado ao sistema produtivo, sendo hoje responsável por quase $50 \%$ da produção de grãos do Brasil. A oferta de carne bovina e suína quadruplicou, enquanto a oferta de frango foi ampliada em 22 vezes. O país deixou de importar alimentos básicos e tornou-se um dos maiores produtores e exportadores mundiais. Além disso, programas de pesquisa específicos conseguiram organizar tecnologias e sistemas de produção para aumentar a eficiência da agricultura familiar e incorporar pequenos produtores no agronegócio, garantindo melhoria na sua renda e bem-estar (EMBRAPA, 2019b).

$\mathrm{Na}$ área de cooperação internacional, a empresa está presente em todos os continentes por meio de parcerias com algumas das principais instituições e redes de pesquisa do mundo. A cooperação científica busca a troca de conhecimentos e avanços na pesquisa científica e tecnológica. Para ajudar nesse esforço, a Embrapa estabeleceu parcerias com laboratórios nos Estados Unidos (1998), Europa (2002), Coreia do Sul (2009) e China (2012) para o desenvolvimento de pesquisas em tecnologias de ponta. Esses "Laboratórios no Exterior" (LABEXs) têm permitido o acesso de pesquisadores da Embrapa, e desses outros países, às mais altas tecnologias em áreas como recursos naturais, biotecnologia, informática, agricultura de precisão, etc. A cooperação técnica atua na esfera da transferência de tecnologia para países em desenvolvimento, atendendo, principalmente, a países da África, América Latina e Caribe (EMBRAPA, 2019b).

No início de 2019, a empresa publicou sua Política de Inovação, tornando-se uma das primeiras instituições públicas a implantar uma política alinhada ao Marco Legal de Ciência, Tecnologia e Inovação (2016) e à Lei de Inovação (2004). Está fundamentada em premissas que pretendem dar mais agilidade para a Embrapa atuar no ambiente de inovação e negócios, como critérios de excelência científica e tecnológica, papel central da inovação como estratégia para o desenvolvimento competitivo e sustentável da agropecuária brasileira e gestão da inovação orientada para a geração de resultados e de valor aos públicos de interesse. Com isso, a empresa espera ganhar agilidade e maior flexibilidade para estabelecer novos arranjos, dinâmicas e modelos de negócios. A política também estabelece o Núcleo de Inovação Tecnológica (NIT) como a estrutura tática de gestão da Política de Inovação, por meio da Secretaria de Inovação e Negócios (SIN), ligada à Diretoria Executiva de Inovação e Tecnologia (EMBRAPA, 2019b).

O documento traz seis diretrizes de atuação no ambiente de inovação que permitem celebrar contratos para outorga de direito de uso ou de exploração e de encomenda tecnológica; estruturar fundos e mecanismos para o financiamento da inovação; participar e/ou criar parques e polos tecnológicos e compartilhar e/ou permitir a utilização, por prazo determinado, de suas estruturas; estimular e reconhecer talentos, por meio de capacitação e de mecanismos de reconhecimento e recompensa para resultados inovadores; e participar minoritariamente do capital 
social de empresas com a finalidade de desenvolver produtos, processos ou serviços inovadores nas áreas de atuação da Embrapa. Em 2020, pelo menos 18 normas serão revisadas e/ou elaboradas para viabilizar as diretrizes previstas na política, compondo o arcabouço normativo de inovação e negócios da empresa (EMBRAPA, 2019b).

\section{Metodologia}

Para atingir os objetivos propostos, foi realizado um estudo de caso, de natureza exploratória e descritiva, com abordagem mista (quanti-qualitativa) e fontes de dados primárias e secundárias. As abordagens exploratória e descritiva foram adotadas com o objetivo de aproximação de uma área, permitindo a descrição de um fenômeno e/ou o estabelecimento de relações entre variáveis (GIL, 1995).

A caracterização como um estudo de caso se justifica por se tratar de estudo profundo de um ou poucos objetos, neste caso, a gestão de proteção de marcas da Embrapa, permitindo conhecimento amplo e detalhado sobre o tema. De acordo com Yin (2001), o estudo de caso é uma estratégia de pesquisa que visa a examinar um fenômeno contemporâneo dentro de seu contexto, buscando analisar uma situação específica. Ajuda a compreensão dos fenômenos individuais, organizacionais e sociais, permitindo uma investigação que preserva as características do objeto da pesquisa, como os processos organizacionais e sua relação com o contexto social entre outros.

A escolha da Empresa Brasileira de Pesquisa Agropecuária (Embrapa) se justifica pela importância de suas contribuições para a sociedade brasileira. Como instituição governamental dedicada à pesquisa agropecuária, a Embrapa ajudou o país a superar as barreiras que limitavam a produção de alimentos, fibras e energia, tornando a agropecuária brasileira uma das mais eficientes e sustentáveis do planeta. Em seu Balanço Social mais recente, em 2018, a empresa demonstrou que para cada real investido, obteve-se um retorno de $\mathrm{R} \$ 12,16$ (doze reais e dezesseis centavos) para o país. Diante da relevância da instituição no contexto nacional e internacional, a gestão da proteção das marcas é estratégica, pois estas podem ser importantes ativos de valor para a empresa.

A abordagem mista, a quanti-qualitativa, contempla aspectos dos dois métodos, possibilitando tanto a quantificação e percentualização de dados como a análise de seus resultados em termos críticos qualitativos. A pesquisa quantitativa atua em níveis de realidade e objetiva trazer à luz dados, indicadores e tendências observáveis, enquanto a qualitativa busca aprofundar a complexidade de fenômenos, fatos e processos particulares (MINAYO; SANCHES, 1993). Assim, a associação das abordagens quantitativas e qualitativas ajudou a compreender melhor a realidade investigada e a interpretação dos dados obtidos.

Os dados secundários foram coletados das bases de dados do Instituto Nacional da Propriedade Intelectual (INPI), da World Intellectual Property Organization (WIPO) e da Trade Mark Search (TMview), compreendendo as marcas registradas, utilizando-se como termo de busca a denominação "Embrapa" na titularidadeno período de 1970 a 2018. Observou-se a quantidade de depósitos, a situação atual, as principais classes de registro, entre outros dados acerca dos registros e suas correlações. Também foram consultados documentos institucionais existentes sobre o tema, como a recém-lançada Política de Inovação da empresa. 
A partir da análise dos dados primários, foram realizadas entrevistas semiestruturadas com o objetivo de elucidar questões sobre a gestão da proteção de marcas da Embrapa. Foi elaborado um roteiro prévio, norteado por algumas questões-chave, porém aberto para que os informantes pudessem discorrer sobre o tema. Rodríguez Gómez, Gil Flores e García Jiménez (1996) pontuam que um bom informante é aquele que dispõe de conhecimento, experiência no tema investigado e habilidade de reflexão. Uma área da empresa foi identificada como responsável pelo tema: a Gerência de Marketing da Secretaria de Inovação e Negócios, localizada em Brasília no Distrito Federal. Para identificar outros informantes-chave com conhecimento sobre o tema, foi utilizada a técnica de amostragem snowball ou bola de neve, apresentada por Goodman (1961), em que o primeiro contato "semente" indicou outras pessoas de seu conhecimento para colaborar na investigação, resultando em três entrevistados.

Os dados coletados foram analisados com o auxílio de tabelas e gráficos que permitiram verificar tendências e correlações. As entrevistas foram transcritas, e os dados foram organizados, analisados e classificados par se compreender o fenômeno aqui estudado.

\section{Resultado e Discussão}

A pesquisa foi realizada a partir da base de dados e da série estatística disponibilizadas pelo INPI, e, como método avaliativo, buscou-se informações em outras bases para apurar dados complementares. As entrevistas foram realizadas a partir de roteiro prévio e de um primeiro contato "semente". Dessa forma, foram consultados o Gerente de Marketing e a Coordenadora do Suporte Jurídico à Inovação, ambos vinculados à Secretaria de Inovação e Negócios (SIN), e o Supervisor de Comunicação Corporativa, vinculado à Secretaria Geral.

A partir de buscas por titularidade dos pedidos de registros de marca no período de 1970 até junho de 2018, utilizando o termo "embrapa", foram encontradas 19 titularidades no INPI, sendo que, destas, nove são vinculadas à empresa, conforme demonstrado no Quadro 1. Entre essas titularidades, apenas quatro apresentam pedidos de registro de marca no INPI. Em consulta à base do TMView foram encontradas as mesmas nove titularidades que tinham vínculo com a empresa.

Quadro 1 - Registro de Marca com a titularidade EMBRAPA - Série Histórica 1975 a 2019

\begin{tabular}{|c|c|}
\hline \multicolumn{1}{|c|}{ TitulaRIDADE } & NúMERO DE REGISTROS \\
\hline Ceres - Fundação de Seguridade Social dos Sistemas Embrapa e Embrater & $\mathrm{x}$ \\
\hline Coop de Economia e Cred. dos Empregados da Embrapa & $\mathrm{x}$ \\
\hline Embrapa - Empresa Brasileira de Pesquisa Agropecuária & 468 \\
\hline Embrapa Centro Nacional de Pesquisa de Milho e Sorgo & 2 \\
\hline Embrapa Instrumentação Agropecuária & 4 \\
\hline Embrapa - Centro Nacional de Pesquisa de Gado de Leite & 10 \\
\hline Embrapa - Empresa Brasileira de Pesquisa Agropecuária & $\mathrm{x}$ \\
\hline Proembrapa - Associação dos Profissionais da Embrapa & $\mathrm{x}$ \\
\hline
\end{tabular}

Fonte: INPI (2019) 
A partir dos critérios de busca já citados, foram encontrados 484 processos de registro de marca no INPI, enquanto no TMView foram encontrados apenas 456. A diferença apresentada pelas duas bases dá-se pela forma da especificação de busca em ambos os casos, sendo que o TMView é uma plataforma mais robusta, que possibilita ao usuário realizar uma busca mais minuciosa. Todavia, neste estudo, optou-se por priorizar os dados obtidos na base do INPI, por se tratar do órgão oficial de registro de marcas no país, recorrendo-se aos dados do TMView como forma complementar para o entendimento do fenômeno estudado.

Entre os registros citados, foram levados em consideração neste estudo: Embrapa - Empresa Brasileira de Pesquisa Agropecuária; Embrapa Centro Nacional de Pesquisa de Milho e Sorgo; Embrapa Instrumentação Agropecuária; e Embrapa - Centro Nacional de Pesquisa de Gado de Leite.

Os dados obtidos na plataforma do INPI (Gráfico 1) demonstram o aumento do número de pedidos de registros da Embrapa ao longo do tempo. Somente no ano de 1999, apresentou seu resultado mais expressivo, com 83 pedidos encaminhados. Como é possível verificar também no Gráfico 1, os números de depósitos de marcas não seguem uma tendência ordenada, havendo uma oscilação de ano em ano. Entretanto, é evidente o crescente nos pedidos de registro solicitados pela empresa.

Gráfico 1 - Depósitos de registro de marcas no Brasil - Série Histórica 1970 a 2018

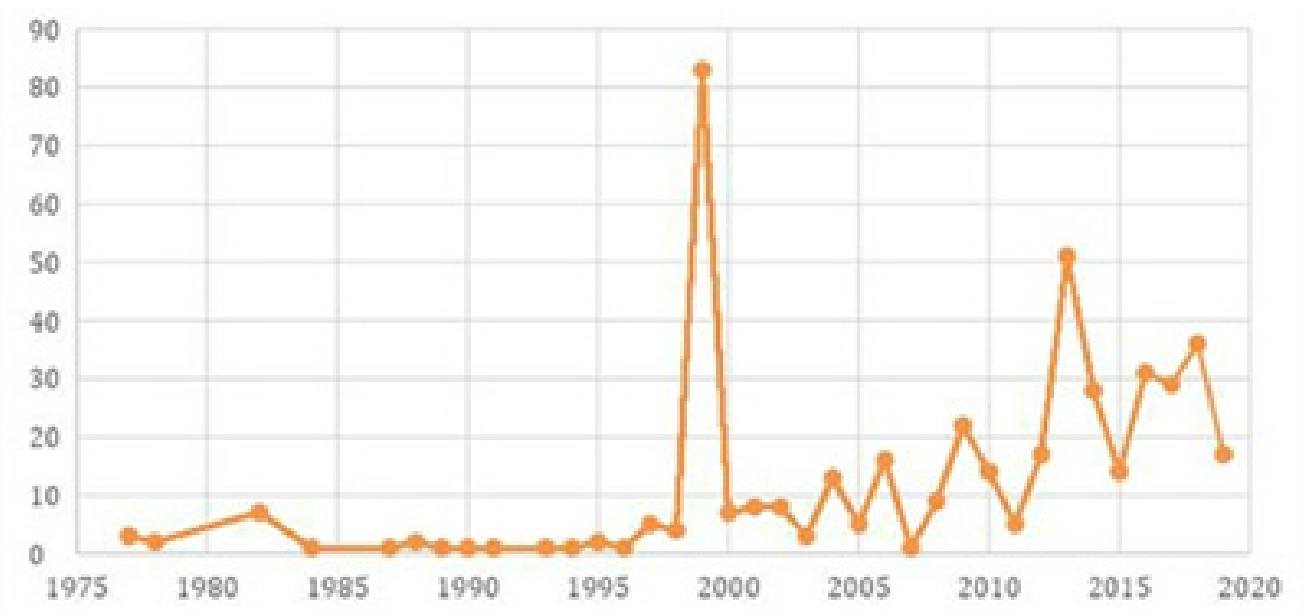

Fonte: INPI (2019)

Nas entrevistas, descobriu-se que, no ano de 1999, foi realizado um esforço por parte da empresa para efetivar os registros das marcas nominativas e das siglas que a representam, de todas as Unidades da Embrapa existentes na época, o que explica esse pico no número de pedidos junto ao INPI. Cabe também destacar que a titularidade Embrapa - Empresa Brasileira de Pesquisa Agropecuária concentra grande parte dos pedidos em função da forma como o processo está estruturado na empresa, sendo pouco comum encontrar registros diretamente na titularidade das Unidades. Portanto, não foi possível realizar um levantamento distribuindo os pedidos por Unidades da Embrapa solicitantes.

Nas entrevistas realizadas, ficou evidenciado que o processo de proteção de marcas não está documentado em norma ou documento orientador, porém segue o mesmo rito dos demais ativos como cultivares e patentes, já consolidados dentro da empresa. As Unidades elaboram 
uma Nota Técnica, solicitando a proteção, e encaminham os formulários já preenchidos para a SIN, na Sede, que avalia, aprimora e efetiva o pedido junto ao INPI. Segundo o Gerente de Marketing, quando se trata de marca comercial, a área de Propriedade Intelectual solicita um posicionamento da gerência, para que seja dado um parecer quanto à adequação da estratégia, à existência de marcas similares e à vinculação a algum modelo de negócio. Quanto às orientações, dois entrevistados mencionaram o documento orientador para criação e uso de selos e marcas que aborda principalmente a questão da identidade visual e o uso correto da marca Embrapa. Um novo documento está em elaboração e deve abordar também a questão da proteção dessas marcas geradas pela empresa.

Específico sobre marcas e sobre ativos, nós estamos terminando agora uma orientação para lançamento de tecnologias, com uma série de critérios e tal, e estamos quase finalizando uma primeira proposta de arquitetura de marca comercial da Embrapa, que nós não tínhamos isso. Temos o documento orientador de marcas como um todo, mas se refere principalmente às marcas institucionais, e nós não tínhamos esse recorte, por exemplo, para marcas coletivas, marcas de produtos e serviços, marca conceito [...] Ela era vinculada somente com a preocupação mais da lógica da arquitetura e do ponto de vista visual da marca, não visto como uma ferramenta de negócios, um ativo. (Entrevistado 1)

Quanto ao aumento no número de registros, existe um entendimento de que há um esforço por parte da empresa no sentido de promover a lógica da marca como um ativo, como um instrumento de negócio. No entanto, não foi evidenciada uma ação coordenada por parte da Sede no sentido de prospectar marcas criadas ou em uso pelas Unidades e induzir de forma mais efetiva a proteção, sendo que, na maior parte, os registros são realizados por solicitação das Unidades.

Teve uma, digamos assim, uma promoção significativa da lógica de marcas, pela atual secretaria e, principalmente pela Diretoria de Inovação e Tecnologia, então isso foi muito divulgado, foi muito promovido, inclusive pelo próprio Diretor, para que as Unidades iniciassem um processo de avaliação e percepção quanto à lógica de uso de marcas como instrumento de negócio. E, a partir disso, obviamente as Unidades [...] começaram a propor. (Entrevistado 1)

Verificou-se na entrevista que a área de Comunicação Corporativa questiona se é interessante para a empresa "multiplicar" marcas ou se apoiar na marca Embrapa, que já é amplamente reconhecida.

Então às vezes, você está criando marca para coisas desnecessárias, quando é mais interessante se apoiar na marca Embrapa e usar outras formas de identidade. Embora nunca tenha sido feita uma pesquisa de valoração, sabemos que a marca da Embrapa é um ativo forte, valioso, importante. As pessoas conhecem a Embrapa e associam a valores positivos. Então essa é uma discussão que a empresa precisa fazer. (Entrevistado 2)

Esses relatos demonstram uma preocupação da empresa em aprimorar esse processo, gerando valor a partir do ativo marca. 
No Gráfico 2, pode-se verificar como as marcas estão distribuídas em relação à forma de apresentação. Evidenciou-se que a Embrapa possui o registro em sua grande maioria (60\%) marcas nominativas, seguidas pelas mistas com $38 \%$ e figurativas com apenas $2 \%$.

Gráfico 2 - Formas de apresentação das marcas da Embrapa - Série Histórica 1975 a 2018

\section{INPI}

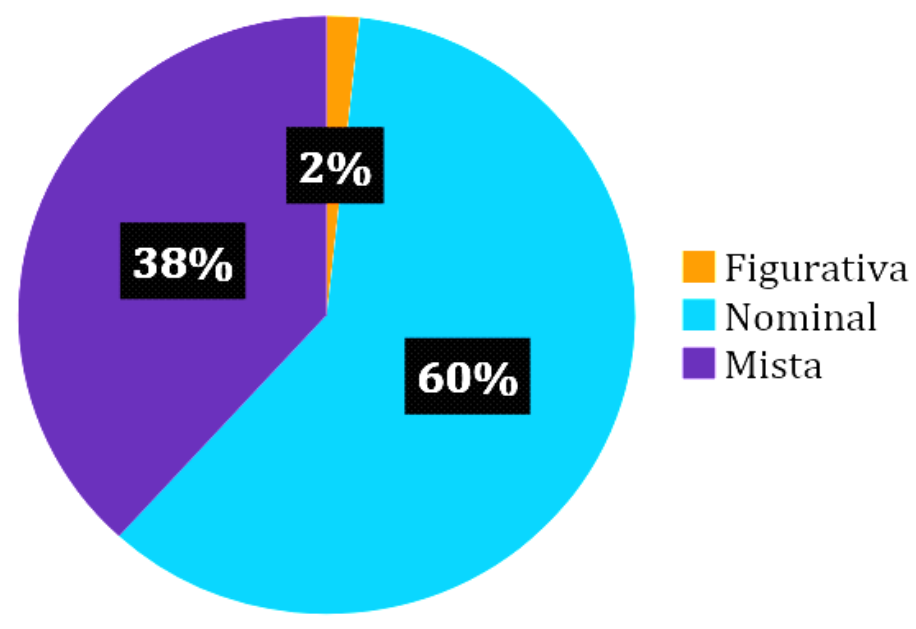

Fonte: INPI (2019)

Entende-se que esse número expressivo $(60 \%)$ de marcas classificadas como nominativas dá-se devido ao fato de a empresa registrar os nomes e as siglas de todas as suas unidades em todo o território brasileiro. Também contribuem, aqui, os nomes de soluções tecnológicas e eventos promovidos pela instituição.

A respeito do registro de marca no exterior, foram encontrados na plataforma de busca TMView apenas três registros, sendo dois na Argentina e um no Uruguai, ambos se referindo a uma solução tecnológica oferecida pela empresa. A busca também foi realizada nas bases da World Intellectual Property Organization (WIPO) e United States Patent and Trademark Office (USPTO), não retornando nenhum resultado. Considerando a presença internacional da empresa por meio dos Labexs e das cooperações internacionais, entende-se que é necessário que seja realizada uma análise, um olhar para a questão do registro internacional da marca, principalmente da marca Embrapa nos países com os quais se tem relação. Para ativos como patentes, a questão, atualmente, está prevista em norma, e a empresa conta uma carteira de mais de um milhão de reais ao ano de manutenção desses ativos no exterior.

[...] hoje é norma, existe uma norma para isso, que os ativos que deseja se proteger internacionalmente, isso tem que ser feito junto com um parceiro que faz exploração comercial no exterior. Então a gente não protege mais, essa é a mesma lógica, não é distinto para marca ou se é um ativo físico, não é separado, então vale pra tudo. Que qualquer ativo que seja objeto de patente internacional, para futura exploração comercial ele tem que ser feito em comum com parceiro que faça o aporte financeiro necessário para sua proteção fora. Existem algumas excepcionalidades, mas a normativa que estabelece isso, estabelece desta forma. (Entrevistado 1) 
Para entender a distribuição das classes, foram observados os registros segundo a Classificação Internacional de Produtos e Serviços de Nice (NCL). De acordo com os dados de registro de marcas do INPI, mesmo antes de 1999, quando houve o pico de registro de marcas, a Embrapa já apresentava uma tendência de registrar marcas nominativas (Gráfico 3), e, em sua maioria (98\%), essas marcas são classificadas como NCL (8) 42, que são as destinadas para o uso de: serviços científicos e tecnológicos, pesquisa e desenho relacionados a estes; serviços de análise industrial e pesquisa; concepção, projeto e desenvolvimento de hardware e software de computador; serviços jurídicos (INPI - Classificação de Nice - $8^{a}$ edição Parte II).

Gráfico 3 - Classes dos registros de Marcas Embrapa - INPI - Série Histórica 1970 a 2018

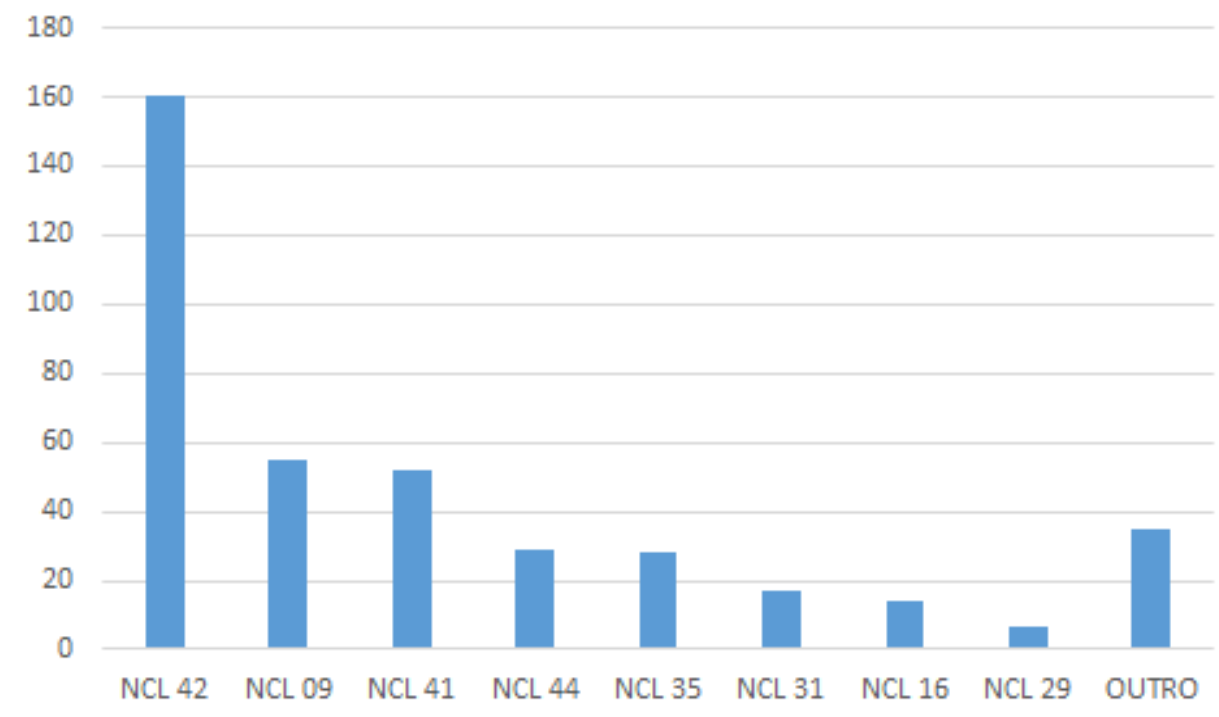

Fonte: INPI (2019)

Para entender as principais classes dispostas no estudo, o Quadro 2 mostra as classes com maior número de registros e sua definição.

Quadro 2 - Categorias de NICE

\begin{tabular}{|c|c|}
\hline NCL & DESCRIÇÃo \\
\hline 09 & $\begin{array}{l}\text { Aparelhos e instrumentos científicos, de pesquisa, de navegação, geodésicos, fotográficos, } \\
\text { cinematográficos, audiovisuais, ópticos, de pesagem, de medição, de sinalização, de detecção, } \\
\text { de teste, de inspeção, de salvamento e de ensino; Aparelhos e instrumentos para conduzir, } \\
\text { interromper, transformar, acumular, regular ou controlar a distribuição ou o uso de eletricidade; } \\
\text { Aparelhos e instrumentos para gravar, transmitir, reproduzir ou processar som, imagens ou dados; } \\
\text { Mídias gravadas e baixáveis, programas de computador, mídias virgens digitais ou analógicas } \\
\text { para gravação e armazenamento; Mecanismos para aparelhos operados com moedas... }\end{array}$ \\
\hline 35 & Propaganda; gestão de negócios; administração de negócios; funções de escritório. \\
\hline 41 & Educação, provimento de treinamento; entretenimento; atividades desportivas e culturais. \\
\hline 42 & $\begin{array}{l}\text { Serviços científicos e tecnológicos, pesquisa e desenho relacionados a estes; } \\
\text { serviços de análise industrial e pesquisa; concepção, projeto e desenvolvimento } \\
\text { de hardware e software de computador; serviços jurídicos. }\end{array}$ \\
\hline 45 & $\begin{array}{l}\text { Serviços pessoais e sociais prestados por terceiros, para satisfazer necessidades } \\
\text { de indivíduos; serviços de segurança para proteção de bens e pessoas. }\end{array}$ \\
\hline
\end{tabular}

Fonte: Elaborado com base nos dados do INPI (2019) 
Destaca-se ainda que, no período estudado, encontrou-se uma forte demanda por registro de marcas em classes de serviços, o que pode demonstrar uma tendência da empresa em valorizar essa categoria em detrimento dos produtos. Quando levada em consideração a situação atual dos pedidos junto ao INPI, conforme mostra o Gráfico 4, verifica-se que $71 \%$ dos registros concedidos estão ativos, demonstrando que, além de ter um número expressivo de marcas registradas, a empresa está conseguindo mantê-las de forma adequada. Percentuais próximos também são expressados na plataforma de pesquisa da TMView. Somando os pedidos arquivados, extintos e indeferidos, estes somam $17 \%$, enquanto $11 \%$ se tratam de pedidos recentes, que ainda estão aguardando análise.

Gráfico 4 - Situação das marcas da Embrapa - Série Histórica 1970 a 2018

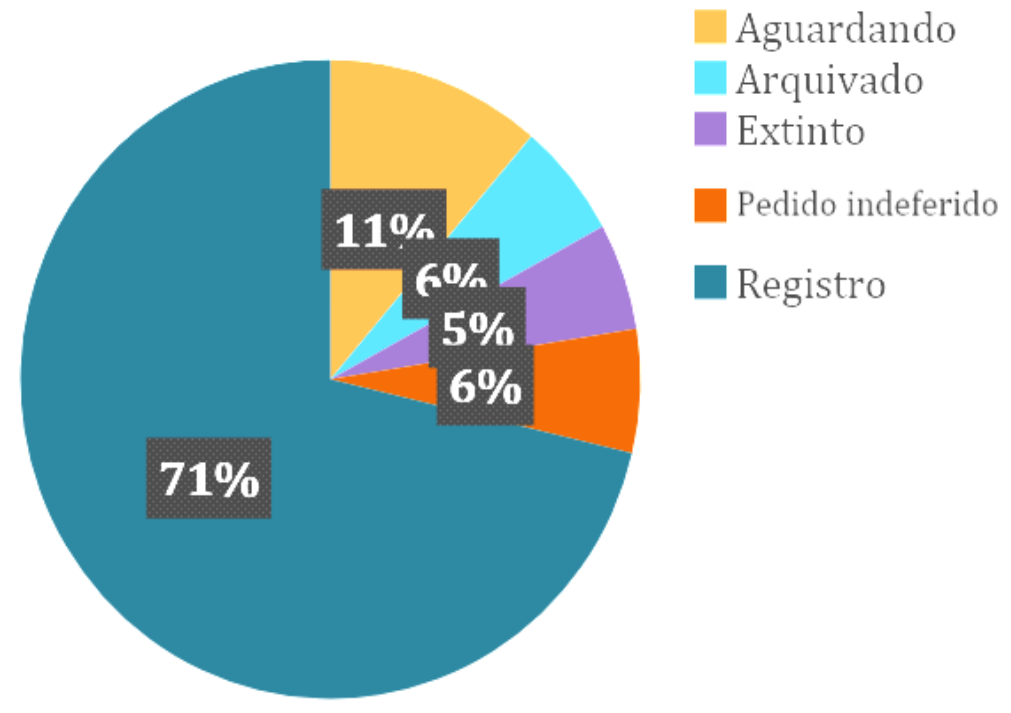

Fonte: INPI (2019)

Com objetivo de demonstrar as principais fragilidades apresentadas nos pedidos de registros de marca analisados, apresenta-se no Gráfico 5 os principais motivos de indeferimento, arquivamento ou extinção dos pedidos de registro, por meio da análise dos artigos que foram citados.

Gráfico 5 - Situação das marcas da Embrapa - Série Histórica 1975 a 2019

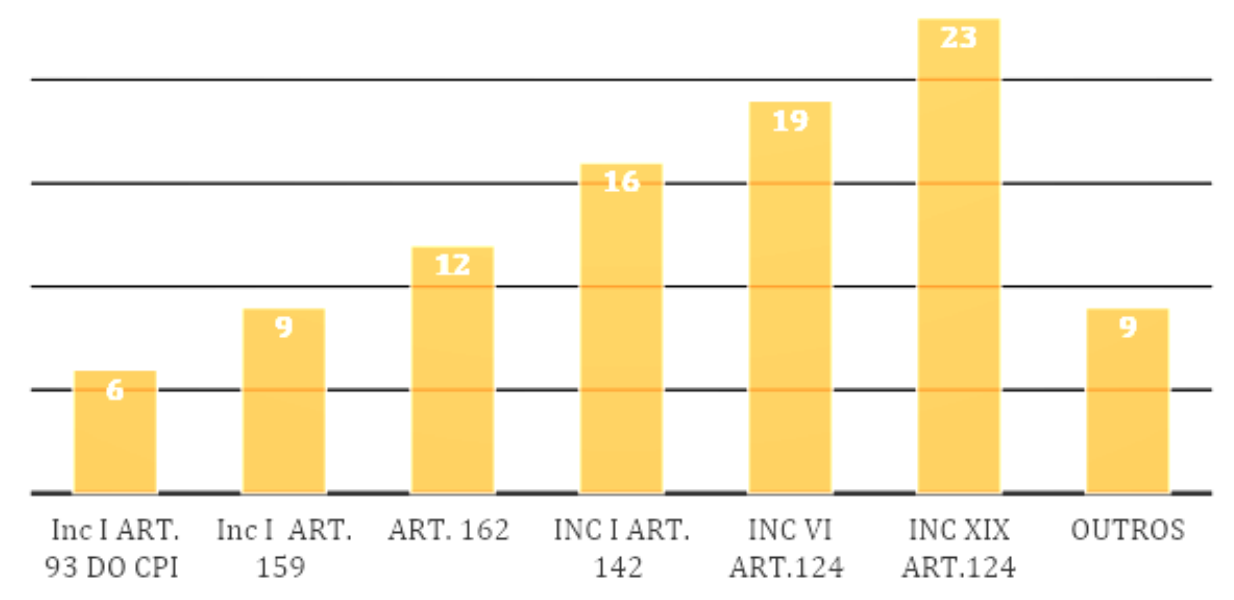

Fonte: INPI (2019) 
Entre os principais impedimentos no processo de registro e manutenção da marca estão os incisos VI e XIX do artigo 124 da LPI (Quadro 3), que em sua totalidade chegam a $42 \%$. Isso significa que os pedidos de registros de marcas da Embrapa na sua maioria não são aceitos por serem considerados de caráter genérico ou possuírem reprodução ou imitação, no todo ou em parte, de signo pertencente a terceiro.

Quadro 3 - Principais motivos de recusa das marcas da Embrapa - Série Histórica 1970 a 2018

\begin{tabular}{|c|c|c|}
\hline \multicolumn{3}{|r|}{ LEI N. 9.279, DE 14 DE MAIO DE 1996.} \\
\hline Art. 124 & VI & $\begin{array}{l}\text { Sinal de caráter genérico, necessário, comum, vulgar ou simplesmente descritivo, } \\
\text { quando tiver relação com o produto ou serviço a distinguir, ou aquele empregado } \\
\text { comumente para designar uma característica do produto ou serviço, quanto } \\
\text { à natureza, nacionalidade, peso, valor, qualidade e época de produção ou de } \\
\text { prestação do serviço, salvo quando revestidos de suficiente forma distintiva. }\end{array}$ \\
\hline Art. 124 & XIX & $\begin{array}{l}\text { Reprodução ou imitação, no todo ou em parte, ainda que com acréscimo, de marca } \\
\text { alheia registrada, para distinguir ou certificar produto ou serviço idêntico, semelhante } \\
\text { ou afim, suscetível de causar confusão ou associação com marca alheia }\end{array}$ \\
\hline Art. 142 & I & Pela expiração do prazo de vigência. \\
\hline Art. 159 & I & Não respondida a exigência, o pedido será definitivamente arquivado. \\
\hline Art. 162 & & $\begin{array}{l}\text { O pagamento das retribuições, e sua comprovação, relativas à expedição do } \\
\text { certificado de registro e ao primeiro decênio de sua vigência, deverão ser } \\
\text { efetuados no prazo de } 60 \text { (sessenta) dias contados do deferimento. }\end{array}$ \\
\hline
\end{tabular}

Fonte: INPI (2019)

Também é importante salientar as perdas pela falta de cumprimento do artigo 162 da LPI, que trata sobre o período de pagamento das retribuições relativas à expedição do certificado de registro e ao primeiro decênio de sua vigência; o que mostra uma fragilidade no gerenciamento desses ativos. Quando questionado a respeito dos insucessos e dos motivos de indeferimento de registros, um dos entrevistados atribui à falta de treinamento e orientação das equipes.

Falta orientação e falta capacitação também das equipes. Falta coorientação da Sede em alguns aspectos, para que poderiam minimizar estes efeitos, e também falta capacitação das equipes internas para que elas possam de forma proativa evidenciar esse tipo de problema, de equívoco, e evitar que isso ocorra, pois, muitas vezes, isso pode ser evitado. (Entrevistado 1)

Buscar uma metodologia ou uma forma sistemática para desenvolver os registros de marca da empresa é fundamental, pois os procedimentos junto ao INPI são, de forma geral, onerosos e burocráticos, o que demanda investimento de recursos financeiros e tempo nesses processos.

Em relação ao licenciamento de uso das marcas, a área responsável não soube informar o número de contratos vigentes, mas informou que todos os licenciamentos de tecnologias e cultivares estão atrelados ao licenciamento de marca, principalmente do selo de Tecnologia Embrapa. Em consulta ao Sistema de Acompanhamento de Instrumentos Contratuais (SAIC), verificou-se que, de um total de 25.215 contratos de licenciamento, 1.189 estão vigentes. Dessa forma, pode-se inferir que a empresa conta hoje com mais de mil contratos vigentes envolvendo 
licenciamento de uso de marca. Por padrão adotado na empresa, esse tipo de contrato tem vigência de 20 anos e grande parte permite o uso da marca sem exclusividade.

A empresa também atua quando identifica uso ou associação indevida da marca a eventos, produtos e serviços. Um dos entrevistados lembrou de algumas situações já ocorridas e complementou "[...] mostrando que tem um monte de gente querendo se associar à marca, mostrando a importância e a força que ela tem" (Entrevistado 2). Entretanto, não há um monitoramento proativo, a Embrapa age com base em denúncias que, na sua maioria, partem dos próprios empregados. "Outra forma de identificar esses casos é no momento em que são realizadas buscas de anterioridade para novos registros" (Entrevistado 3).

\section{Considerações Finais}

Objetivou-se identificar, por meio de estudo de caso da Empresa Brasileira de Pesquisa Agropecuária, a Embrapa, escolhida por sua relevância no Sistema Nacional de Pesquisa Agropecuária, as potencialidades e as fragilidades de sua gestão de proteção de marcas.

Ficou evidenciado que há um crescimento nos registros aliado a um esforço da empresa em valorizar o ativo marca. A empresa possui um processo para encaminhamento de registro de marcas relativamente conhecido, mas não documentado. Apesar do lançamento da recente Política de Inovação da empresa no nível estratégico, no nível tático e operacional, há a necessidade latente de documentação do processo, conectando os diferentes elos da gestão da marca que ocorrem em áreas diferentes.

Ainda há oportunidades para melhoria na redução do índice de pedidos recusados, apontando para uma lacuna na orientação e na capacitação das equipes para proteção e execução de forma correta dos procedimentos de registros junto ao INPI.

Além disso, percebeu-se que há uma intenção da empresa em investir mais no ativo marca. Dessa forma, a clareza em relação ao processo de proteção e a devida internalização deste, além da capacitação das equipes da empresa que tratam do tema, se tornam fundamentais para colocar a Embrapa em posição de destaque no mercado.

Recomenda-se também que a empresa avalie o registro da marca Embrapa em outros países, principalmente nos países em que ela mantém operações, de forma a evitar que terceiros a utilizem ou se associem a ela indevidamente.

Por último, registra-se que embora os resultados não possam ser generalizados, o estudo pode contribuir para ampliação dos conhecimentos e compreensão sobre a realidade e as práticas em empresas públicas do mesmo ramo da Embrapa, sobretudo pelo fato de a empresa ser referência em pesquisa, desenvolvimento e inovação para a agropecuária no Brasil e no mundo.

Os dados obtidos também podem servir como norteadores para a aplicação de estudos futuros sobre a gestão de proteção de marcas da Empresa e sua evolução.

\section{Referências}

ABAPI - ASSOCIAÇÃO BRASILEIRA DOS AGENTES DA PROPRIEDADE INDUSTRIAL.

Propriedade Industrial no Brasil - 50 anos de História. São Paulo: ABAPI, 1998. 132p.

Disponível em: http:/www.abapi.org.br/abapi2014/livros/abapi50anos0.pdf. Acesso em: 10 jun. 2019 
ALBUQUERQUE, V. V. A rose by any other name: conformações do direito de marca no mercado farmacêutico. 2015.

BALDIN, N.; MUNHOZ, E. M. B. Snowball (bola de neve): uma técnica metodológica para pesquisa em educação ambiental comunitária. In: X CONGRESSO NACIONAL DE EDUCAÇÃO. PUCPR: Curitiba, 2011. Anais [...], Curitiba, de 7 a 10 de novembro de 2011.

BRAND FINANCE. Global 500 2019: The annual report on the world's most valuable and strongest brands. [2019]. Disponível em: https://brandfinance.com/images/upload/global_500_2019_ free.pdf. Acesso em: 7 jun. 2019.

BRASIL. Lei n. 9.279, de 14 de maio de 1996. Regula direitos e obrigações relativos à propriedade industrial. Disponível em: http://www.planalto.gov.br/ccivil_03/leis/19279.htm. Acesso em: 9 jun. 2019.

CRESCITELLI, E.; STEFANINI, A. O licenciamento de marcas estudo de caso: Mattel do BrasilMarca Barbie. In: X SEMEAD - SEMINÁRIOS EM ADMINISTRAÇÃO FEA-USP. São Paulo. Anais eletrônicos [...], São Paulo, 2007.

DE CASTRO, M. J.; RODRIGUES TAPAJÓS, S.; DOS SANTOS, J. A. B. A proteção marcária das empresas de serviços de contabilidade no Brasil: uma visão com base em dados do INPI. Razón y Palabra, [S.1.], v. 21, n. 97, 2017.

EMBRAPA - EMPRESA BRASILEIRA DE PESQUISA AGROPECUÁRIA. [2019a]. Disponível em: www.embrapa.br/quem-somos. Acesso em: 22 maio 2019.

EMBRAPA - EMPRESA BRASILEIRA DE PESQUISA AGROPECUÁRIA. Intranet. [2019b].

Disponível em: https://www.embrapa.br/group/intranet/inicial. Acesso em: 22 maio 2019.

EMBRAPA - EMPRESA BRASILEIRA DE PESQUISA AGROPECUÁRIA. Balanço Social 2018. Disponível em: https://bs.sede.embrapa.br/2018. Acesso em: 22 maio 2019.

GIL, A. C. Métodos e técnicas de pesquisa social. São Paulo: Atlas, 1995.

GOODMAN, L. Snowball Sampling. Annals of Mathematical Statiscs, [S.1.], v. 32, p. 148-170, 1961. Disponível em: https://www.jstor.org/stable/2237615. Acesso em: 22 maio 2019.

INPI - INSTITUTO NACIONAL DA PROPRIEDADE INDUSTRIAL. Manual de Marcas. 3. ed. 1. rev. em 2 de outubro de 2019. Disponível em: http://manualdemarcas.inpi.gov.br/projects/manual/ wiki/Manual_de_Marcas. Acesso em: 5 maio 2020.

INPI - INSTITUTO NACIONAL DA PROPRIEDADE INDUSTRIAL. Site institucional. [2020]. Disponível em: http://www.inpi.gov.br/. Acesso em: 5 maio 2020.

MATTAR, F. N. Pesquisa de Marketing. São Paulo: Atlas, 2001.

MINAYO, M. C. S.; SANCHES, O. Quantitativo-Qualitativo: Oposição ou complementaridade?

Cadernos de Saúde Pública, Rio de Janeiro, v. 9, n. 3, p. 239-262, jul.-sep. 1993. Disponível em: http://www.scielo.br/pdf/\%0D/csp/v9n3/ 02.pdf. Acesso em: 22 maio 2019.

OMPI - WORLD INTELLECTUAL PROPERTY ORGANIZATION. Intellectual Property

Handbook. [2004]. Disponível em: https://www.wipo.int/edocs/pubdocs/en/intproperty/489/wipo_ pub_489.pdf. Acesso em: 7 jun. 2019.

PASTORE, C. M. A. Gestão de Marcas. Curitiba: Intersaberes, 2018. 
RODRÍGUEZ GÓMEZ, G.; GIL FLORES, J.; GARCÍA JIMÉNEZ, E. Metodología de la Investigación Cualitativa. España: Aljibe, 1996.

RODRIGUES, J. et al. Por que marcas corporativas? A percepção de executivos brasileiros sobre os motivos para adotar corporate branding. REAd-Revista Eletrônica de Administração, [S.1.], v. 23, p. 232-261, 2017.

SALVADOR, Alexandre Borba; IKEDA, Ana Akemi; CRESCITELLI, Edson. Gestão de crise e seu impacto na imagem de marca. Gestão \& Produção, [S.1.], v. 24, n. 1, p. 15-24, 2017.

SCHMIDT, L. D. A distintividade das marcas. São Paulo: Saraiva, 2017.

YIN, R. K. Estudo de caso: planejamento e métodos. Porto Alegre: Bookman, 2001.

WIPO - WORLD INTELLECTUAL PROPERTY ORGANIZATION. Intellectual Property

Handbook. [2019]. Disponível em: http://www.wipo.int/edocs/pubdocs/en/intproperty/489/wipo_ pub_489.pdf. Acesso em: 7 jun. 2019.

\section{Sobre os Autores}

\section{Glauber Adenir Soares Preto}

E-mail: glauberpreto@gmail.com

Administrador pela FSG, pós-graduado em Marketing Estratégico pela Fundação Getúlio Vargas (FGV). Consultor de Negócios da aMarker, Mestrando do PROFNIT/IFRS.

Endereço profissional: Av. dos Girassóis, n. 250, São Francisco, Caxias do Sul, RS. CEP: 95110-661.

\section{Cíntia Brenner Acosta Franco}

E-mail: cintia.brenner@gmail.com

Relações Públicas pela UFRGS. Pós-graduada em Gestão do Capital Humano pela Faculdade Porto-Alegrense, Analista A da Empresa Brasileira de Pesquisa Agropecuária, Mestranda do PROFNIT/IFRS.

Endereço profissional: BR 392, km 78, Monte Bonito, Pelotas, RS. CEP: 96115-000.

\section{Kelly Lissandra Bruch}

E-mail: kelly.bruch@ufrgs.br

Doutora em Direito pela Université Rennes I, France em cotutela com a UFRGS. Mestre em Agronegócios pelo CEPAN/UFRGS. Especialista em Direito e Negócios Internacionais pela UFSC. Graduada em Direito pela Universidade Estadual de Ponta Grossa. Professora do Departamento de Direito Econômico e do Trabalho da Faculdade de Direito da UFRGS. Professora do Programa de Pós-Graduação do Centro em Estudos e Pesquisas em Agronegócios - CEPAN/UFRGS. Professora do PROFNIT (Mestrado Profissional em Rede Nacional em Propriedade Intelectual e Transferência de Tecnologia para Inovação) no Ponto Focal IFRS. ORCID: https://orcid. org/0000-0003-2565-0790.

Endereço profissional: Av. João Pessoa, n. 80, Centro Histórico, Porto Alegre, RS. CEP: 90040-000 . 